\title{
Prevalence of Malaria Positive Rapid Diagnostic Test and Antimalarial Treatment in Patients with Fevers in the Accident and Emergency Unit of Effia Nkwanta Regional Hospital, Western Region, Ghana
}

\author{
Verner N. Orish1" ${ }^{*}$, Jones Ofori-Amoah², Innocent Afeke3 ${ }^{3}$ Ibrahim Jamfaru1, Donatus W. Adongo², \\ Kokou H. Amegan-Aho 4
}

${ }^{1}$ Department of Microbiology, School of Medicine, University of Health and Allied Sciences, Ho, Ghana

${ }^{2}$ Department of Pharmacology, School of Medicine, University of Health and Allied Sciences, Ho, Ghana

${ }^{3}$ Department of Medical Laboratory Science, School of Allied Sciences, University of Health and Allied Sciences, Ho, Ghana

${ }^{4}$ Department of Paediatrics, School of Medicine, University of Health and Allied Sciences, Ho, Ghana

Email: *Orishv@yahoo.com

How to cite this paper: Orish, V.N., OforiAmoah, J., Afeke, I., Jamfaru, I., Adongo, D.W. and Amegan-Aho, K.H. (2016) Prevalence of Malaria Positive Rapid Diagnostic Test and Antimalarial Treatment in $\mathrm{Pa}$ tients with Fevers in the Accident and Emergency Unit of Effia Nkwanta Regional Hospital, Western Region, Ghana. Open Access Library Journal, 3: e3097.

http://dx.doi.org/10.4236/oalib.1103097

Received: September 29, 2016

Accepted: October 14, 2016

Published: October 17, 2016

Copyright $\odot 2016$ by authors and Open Access Library Inc.

This work is licensed under the Creative Commons Attribution International

License (CC BY 4.0).

http://creativecommons.org/licenses/by/4.0/

(c) (i) Open Access

\section{Abstract}

Background: Rapid diagnostic test (RDT) is a simpler, easy to read malaria diagnostic test. It was introduced by the World Health Organization (WHO) to supplement the use of microscopy and can be used alone in areas where microscopy is unavailable. Its introduction was necessary to maintain the WHO test-based treatment protocol for malaria, as dependence of microscopy which is the gold standard is not possible in many areas in Sub-Saharan Africa which lack the wherewithal to run efficient laboratory services. WHO strongly recommends that only patients with parasitological confirmation of malaria should be treated with antimalarial drugs. In this study, the prevalence of malaria positive RDT and antimalarial treatment was evaluated in patients presenting with fevers at the outpatient section of the accident and emergency unit of the Effia Nkwanta Regional Hospital, Ghana. Methodology: This was a retrospective study carried out in the outpatient section of the accident emergency unit of Effia Nkwanta Regional Hospital. The outpatient register was reviewed from October 2014 to March 2015, for patients who came with fever. Data on demographics, malaria RDT status and antimalarial treatment were collected and analyzed. Result: A total of 607 patients with fever had their RDT performed. Of these, 131 (21.58\%) were positive for malaria while 467 (78.42\%) were negative. Out of the 131 tested positive, 55 represented patients above 12 years and 76 represent children 
aged 0 to 12 years, $p=0.002$. Fifty children under the age of 5 years tested positive for malaria whereas 26 were above the age 5 years, $p=0.03$. All the 131 positive patients were treated for malaria while 276 out of 476 negative patients were also treated for malaria, $\mathrm{p}<0.001$. Conclusion: Patients positive for malaria RDT in this study were lower. Children were more positive for malaria than adults, with those under 5 years constituting the majority. This study also shows that indiscriminate malaria prescription is still a problem, a situation that should be tackled immediately, to prevent malaria parasite being resistant to current antimalarial drugs.

\section{Subject Areas}

Global Health, Infectious Diseases

\section{Keywords}

Rapid Diagnostic Test, Malaria, Plasmodium falciparum, Antimalarial

\section{Introduction}

Malaria remains a serious health problem in Sub-Saharan Africa [1]. Aside the burden of the disease in the population especially in pregnant women and children less than 5 years, malaria has strained the perennial dilapidated health sector in Africa [2]. Diagnostic lapses in the health sector in sub-Saharan African have taken its toll in the diagnosis and treatment of malaria [3]. There are widespread diagnostic bottlenecks being experienced in hospitals and health centers in rural and urban areas in sub-Saharan Africa [4] [5].

Changes in policy and clinical protocol in the diagnosis and treatment of malaria over the past decade was necessary to overcome the challenges in diagnosis and to accommodate the changing dynamics of malaria burden in the sub region [6] [7]. Presumptive malaria diagnoses based on clinical signs was initially encouraged in the early part of the millennium, especially in children using the integrated management of child hood illness (IMCI) protocol [8]. This was necessary at that time as there was very high burden of malaria among children and prompt treatment was necessary to prevent severe and fatal outcomes [8]. This protocol has long been replaced with a more evidence-based approach that solely depends on parasitological confirmation of malaria before treatment [6] [9].

The gold standard for malaria diagnosis is microscopy [10] [11]. Though not the most sophisticated laboratory procedure, it is still very much lacking in many hospitals and health centers in developing countries [12]. Many hospitals and health centers are without functional laboratories, the few with these facilities are continuously plagued with incessant breakdowns, stock of out of reagents and lack of adequately trained personnel to deliver reliable microscopy results [13] [14]. The above highlighted challenges are the main reasons why a simpler diagnostic alternative for malaria (rapid diagnostic test) was necessary to help ease up the problems [11]. This is the reason why WHO in- 
troduced the malaria rapid diagnostic test (RDT) [11].

Malaria RDT is an antigen-antibody immunochroma to graphic assay which detects malaria antigen using monoclonal antibodies directed against targeted parasite antigen [15]. It is a very simple test which can be performed anywhere, even in the consulting room, with results within 15 minutes. Rapid diagnostic test can be designed to detect the various species of Plasmodium. However, the RDT in sub-Saharan Africa is specific for Plasmodium falciparum, which is the predominant species in the region. Under normal operational conditions, the RDT is very sensitive, specific and reliable, increasing confidence in test result for both clinician and patient [15].

In Ghana, evidence-based malaria diagnosis and treatment is being encouraged [9]. With evidence of declining malaria burden, it is very pertinent that test-based malaria diagnoses and treatment be practiced to prevent the non-treatment of other fatal causes of fever especially in children [16] [17]. Since challenges with microscopy are very common in most hospitals and health centers in Ghana, malaria RDT has been deployed to aid in the diagnoses and treatment of malaria. However, despite the relative availability of RDT in most of these facilities, attitude of physicians and other health workers towards the whole idea of test-based treatment is another problem entirely. There are documented evidences that most health workers disregard negative malaria microscopy and prescribe anti-malarial treatment [9]. This same disregard has also been noticed with RDT [9]. The aim of this study was to assess the prevalence of malaria positive RDT and antimalarial treatment among patients with febrile illness seeking care in the accident and emergency unit of the Effia Nkwanta Regional Hospital, Ghana.

\section{Materials and Methods}

\subsection{Study Site}

This study was conducted at the Effia-Nkwanta Regional Hospital, the only referral hospital, located south-west of Ghana in the Sekondi-Takoradi metropolis. SekondiTakoradi is within the Shama Ahanta east and west municipal region. Effia-Nkwanta Regional Hospital provides services to all other hospitals in the 22 districts and the 13 sub-divisions of the western region.

\subsection{Data Collection}

This was a retrospective study carried out in the accident and emergency unit of the Effia-Nkwanta Regional Hospital, Ghana. The sampling structure was the outpatient register of the accident and emergency unit of patients who came with fever as one of the presenting complaints. Data was collected from October 2014 to March 2015. Information on demographics, clinical and RDT findings were collected. Also whether Anti-malarial treatment was given was noted. All patients with fever as one of their symptoms, and suspected of malaria, were included in this study. Those in the register but whose RDT results were not traceable were excluded. At the triage area and consulting room of accident and emergency unit of the Hospital, malaria parasite diagno- 
ses were performed using Plasmodium falciparum specific RDT kits (Premier Medical Corporation Ltd, Daman India). The rapid response kit detects $P$. falciparum antigens and the presence of two lines in the test kit well indicates plasmodiumfalciparum positive.

\subsection{Statistical Analysis}

All statistical analyses were performed using IBM SPSS Statistics version 21.0 (IBM Corporation, Armonk, NY, USA). Frequency distributions were done for the characteristics of the patient in this study (age, sex, RDT and antimalarial status). These characteristics were further analysed using Pearson $\chi^{2}$ tests. Confidence interval (CI) of $95 \%$ was used to measure the strength of the association and $\mathrm{p} \leq 0.05$ was considered statistically significant.

\subsection{Ethical Issues}

Permission was granted to carry out this study by the Effia-Nkwanta Regional Hospital authorities.

\section{Results}

A total of 607 patients with fever had RDT performed during the study period (October 2014 to March 2015). Of these, 307 were males (50.58\%) while 300 (49.42\%) were females (Table 1). Also as shown in Table 1, 325 (53.54\%) of the patients were above 12 years, $71(11.70 \%)$ were from the age of 5 to 12 years and $211(34.76 \%)$ represented children under the age of 5 years Antimalarial treatments were given to 407 (67.05\%) of the patients while 200 (32.95\%) patients had no treatment. A total of 131 (21.58\%) tested positive for malaria, while $476(78.42 \%)$ were negative for malaria (Table 1$)$.

Table 2 stratified the patients into their malaria RDT status. Malaria RDT were posi-

Table 1. Baseline characteristics of 607 patients who attended the accident and emergency unit.

\begin{tabular}{ccc}
\hline VARIABLES & FREQUENCY & PERCENTAGE (\%) \\
\hline SEX & & \\
MALE & 307 & 50.58 \\
FEMALE & 300 & 49.42 \\
AGE & & \\
$(>12)$ & 325 & 53.54 \\
$5-12$ & 71 & 11.70 \\
$<5$ & 211 & 34.76 \\
RDT & & \\
POSITIVE & 131 & 21.58 \\
NEGATIVE & 476 & 78.42 \\
& & \\
ANTIMALARIA TREATMENT & & 67.05 \\
YES & 407 & 32.95 \\
NO & 200 & \\
\end{tabular}


Table 2. Patients' characteristics stratified by malaria RDT status.

\begin{tabular}{cccc}
\hline Characteristics & RDT positive $(\mathrm{n}=131)$ & RDT negative $(\mathrm{n}=476)$ & $\mathrm{p}$ \\
\hline Age & 55 & 270 & 0.002 \\
$>12$ & 76 & 206 & \\
$0-12$ & & & 0.03 \\
Children & 26 & 45 & \\
$\mathbf{5}-\mathbf{1 2}$ & 50 & 161 & 0.65 \\
$<5$ & & & \\
Sex & 64 & 243 & \\
Male & 67 & 233 & $<0.001$ \\
Female & & 276 & \\
Antimalarial & 131 & 200 & \\
YES & 0 & & \\
NO & & & \\
\hline
\end{tabular}

$N B: \mathrm{n}=$ number of samples. P values were based on Pearson Chi-Squared test for categorical variables. ${ }^{*} \mathrm{n}=76 \mathrm{RDT}$ positive; 206 RTD negative.

tive for 76 children ( 0 - 12 years) and 55 patients above the age of 12 years, $\mathrm{p}=0.002$. Further analysis of the 282 children in this study showed positive malaria RDT for 50 younger children ( $<5$ years) and 26 older children ( $5-12$ years), $\mathrm{p}=0.03$ Malaria RDT were positive for 64 males and 67 females $(p=0.67)$. Anti-malarial treatment was given to the 131 patients positive for malaria RDT and 276 negative for malaria RDT ( $\mathrm{p} \leq$ $0.001)$.

\section{Discussion}

This study evaluated the prevalence of RDT positive result for malaria and the antimalarial prescription pattern for patients with fever at the accident and emergency of Effia-Nkwanta Regional Hospital, Ghana from October 2014 to March 2015.

There were 607 febrile patients who had RDT done on them. This might not be a true representation of the entire population of patients that came in with fever during the 6 months under retrospective review. It is very likely that there were more patients with fever who came during this period that were not tested because of persistent stock out of the RDT test kits. This stock out is a nagging problem in many health institutions in sub-Saharan Africa, especially Ghana [9] [13]. This could also be due to the fact that malaria was not suspected in some patients with fever, therefore RDT was not done.

Out of the total number of patients who had RDT done on them, almost $22 \%$ were RDT positive, while much higher number where RDT negative. This result further shows that malaria is no longer the only major cause of fever in patients as there are evidence of declining burden in the in Ghana [16] [17].

There were more children who tested positive for malaria with the RDT than adults. This supports the fact that children are still at risk of malaria despite the decreasing burden in the region [18]. Children under 5 were significantly the majority of patients 
positive for malaria, a finding consistent with studies showing peak malaria prevalence in younger children in stable malaria transmission areas like Ghana [19]-[21].

All the patients that were positive for malaria had treatment. While this could be a correct practice, it is important to note that RDT could still be positive for weeks even if the patient was successfully treated for malaria. Efforts must be made to investigate for other causes of fever in patients with positive malaria RDT and having prior history for recent antimalarial treatment. It is important to note that over half of the numbers that were negative for malaria were also treated for malaria. This practice of treating malaria without diagnostic confirmation is very common among health care providers [22] [23]. However it has been shown that progressive use of RDT builds the confidence of healthcare providers on its use and subsequently reduces indiscriminate prescription of anti-malarial drugs [24].

\section{Conclusion}

This study showed a low prevalence of malaria RDT diagnoses and an indiscriminate antimalarial treatment for patients with fever. This indiscriminate prescription should be curtailed as evidence based medicine is surely the way to go. Test based diagnoses for malaria should be encouraged at all level of health care. RDT test kits should be supplied regularly to ensure best practice be maintained at all time. Health care workers should be trained and re trained on the benefits of test base diagnoses and treatment of malaria. This will go a long way in reducing the financial loss incurred from prescribing antimalarial drugs indiscriminately and also reducing the incidence of drug resistance.

\section{Limitations}

This study cannot vouch for the accuracy in the procedures used by the health care staff in performing and interpreting the malaria RDT. As simple as RDT might be, the manufacturer's instructions must be strictly adhered to for accurate result to be obtained. So it's possible that this study might not have captured the true prevalence of malaria in the accident and emergency unit. Thus a more prospective study evaluating the efficiency and accuracy of the methods used will be very useful in estimating the true prevalence of malaria and subsequent antimalarial treatment.

\section{Acknowledgements}

Authors thank the Head of Effia-Nkwanta Regional Hospital and the management for allowing them to take data from their hospital.

\section{Conflict of Interests}

The authors have not declared any conflict of interests.

\section{References}

[1] World Health Organization (2014) World Malaria Report 2013. World Health Organization Google Scholar, Geneva. 
[2] World Health Organization (2015) World Malaria Report: 2012. Geneva: WHO, 2012. Fecha de Consulta, 23, 247.

[3] Whitty, C.J., Chandler, C., Ansah, E., Leslie, T. and Staedke, S.G. (2008) Deployment of ACT Antimalarials for Treatment of Malaria: Challenges and Opportunities. Malaria Journal, 7, 1. http://dx.doi.org/10.1186/1475-2875-7-s1-s7

[4] Reyburn, H., Mbatia, R., Drakeley, C., Carneiro, I., Mwakasungula, E., Mwerinde, O. and Greenwood, B.M. (2004) Overdiagnosis of Malaria in Patients with Severe Febrile Illness in Tanzania: A Prospective Study. BMJ, 329, 1212. http://dx.doi.org/10.1136/bmj.38251.658229.55

[5] Oladosu, O.O. and Oyibo, W.A. (2012) Overdiagnosis and Overtreatment of Malaria in Children That Presented with Fever in Lagos, Nigeria. ISRN Infectious Diseases.

[6] World Health Organization (2008) World Malaria Report. World Health Organization, Geneva.

[7] Chandramohan, D., Jaffar, S. and Greenwood, B. (2002) Use of Clinical Algorithms for Diagnosing Malarial. Tropical Medicine \& International Health, 7, 45-52. http://dx.doi.org/10.1046/j.1365-3156.2002.00827.x

[8] World Health Organization (2005) Technical Updates of the Guidelines on the Integrated Management of Childhood Illness (IMCI): Evidence and Recommendations for Further Adaptations.

[9] Baiden, F., Malm, K., Bart-Plange, C., Hodgson, A., Chandramohan, D., Webster, J. and Owusu-Agyei, S. (2014) Shifting from Presumptive to Test-Based Management of MalariaTechnical Basis and Implications for Malaria Control in Ghana. Ghana Medical Journal, 48, 112-122. http://dx.doi.org/10.4314/gmj.v48i2.10

[10] World Health Organization (2006) Guidelines for the Treatment of Malaria. World Health Organization.

[11] Reyburn, H., Mbakilwa, H., Mwangi, R., Mwerinde, O., Olomi, R., Drakeley, C. and Whitty, C.J. (2007) Rapid Diagnostic Tests Compared with Malaria Microscopy for Guiding Outpatient Treatment of Febrile Illness in Tanzania: Randomised Trial. BMJ, 334, 403. http://dx.doi.org/10.1136/bmj.39073.496829.AE

[12] Abreha, T., Alemayehu, B., Tadesse, Y., Gebresillassie, S., Tadesse, A., Demeke, L. and Teshome, D. (2014) Malaria Diagnostic Capacity in Health Facilities in Ethiopia. Malaria Journal, 13, 1. http://dx.doi.org/10.1186/1475-2875-13-292

[13] Fonjungo, P.N., Kebede, Y., Messele, T., Ayana, G., Tibesso, G., Abebe, A. and Kenyon, T. (2012) Laboratory Equipment Maintenance: A Critical Bottleneck for Strengthening Health Systems in Sub-Saharan Africa \& Quest. Journal of Public Health Policy, 33, 34-45. http://dx.doi.org/10.1057/jphp.2011.57

[14] Derua, Y.A., Ishengoma, D.R., Rwegoshora, R.T., Tenu, F., Massaga, J.J., Mboera, L.E. and Magesa, S.M. (2011) Users' and Health Service Providers' Perception on Quality of Laboratory Malaria Diagnosis in Tanzania. Malaria Journal, 10, 1. http://dx.doi.org/10.1186/1475-2875-10-78

[15] Moody, A. (2002) Rapid Diagnostic Tests for Malaria Parasites. Clinical Microbiology Reviews, 15, 66-78. http://dx.doi.org/10.1128/CMR.15.1.66-78.2002

[16] National Malaria Control Programme Ghana Health Service. http://www.ghanahealthservice.org/ghs-subcategory.php?cid=4\&scid=41

[17] Afoakwah, C., Nunoo, J. and Andoh, F.K. (2015) Effect of Insecticide-Treated Bed Net Usage on Under-Five Mortality in Northern Ghana. Malaria Journal, 14, 1. http://dx.doi.org/10.1186/s12936-015-0827-8 
[18] Orish, V.N., Ansong, J.Y., Anagi, I.B., Onyeabor, O.S., Sanyaolu, A.O. and Iriemenam, N.C. (2015) Malaria and Associated Co-Morbidity in Children Admitted with Fever Manifestation in Western Ghana: A Retrospective Study. The Journal of Infection in Developing Countries, 9, 1257-1263. http://dx.doi.org/10.3855/jidc.6316

[19] Obonyo, C.O., Vulule, J., Akhwale, W.S. and Grobbee, D.E. (2007) In-Hospital Morbidity and Mortality Due to Severe Malarial Anemia in Western Kenya. The American Journal of Tropical Medicine and Hygiene, 77, 23-28.

[20] Abdullah, S., Adazu, K., Masanja, H., Diallo, D., Hodgson, A., Ilboudo-Sanogo, E. and Binka, F.N. (2007) Patterns of Age-Specific Mortality in Children in Endemic Areas of SubSaharan Africa. The American Journal of Tropical Medicine and Hygiene, 77, 99-105.

[21] Okiro, E.A., Al-Taiar, A., Reyburn, H., Idro, R., Berkley, J.A. and Snow, R.W. (2009) Age Patterns of Severe Paediatric Malaria and Their Relationship to Plasmodium falciparum Transmission Intensity. Malaria Journal, 8, 1. http://dx.doi.org/10.1186/1475-2875-8-4

[22] Polage, C.R., Bedu-Addo, G., Owusu-Ofori, A., Frimpong, E., Lloyd, W., Zurcher, E. and Petti, C.A. (2006) Laboratory Use in Ghana: Physician Perception and Practice. The American Journal of Tropical Medicine and Hygiene, 75, 526-531.

[23] Chandler, C.I., Jones, C., Boniface, G., Juma, K., Reyburn, H. and Whitty, C.J. (2008) Guidelines and Mindlines: Why Do Clinical Staff Over-Diagnose Malaria in Tanzania? A Qualitative Study. Malaria Journal, 7, 1. http://dx.doi.org/10.1186/1475-2875-7-53

[24] Thiam, S., Thior, M., Faye, B., Ndiop, M., Diouf, M.L., Diouf, M.B. and Lee, E. (2011) Major Reduction in Anti-Malarial Drug Consumption in Senegal after Nation-Wide Introduction of Malaria Rapid Diagnostic Tests. PloS One, 6, e18419.

http://dx.doi.org/10.1371/journal.pone.0018419

\section{Submit or recommend next manuscript to OALib Journal and we will provide best service for you:}

- Publication frequency: Monthly

- 9 subject areas of science, technology and medicine

- Fair and rigorous peer-review system

- Fast publication process

- Article promotion in various social networking sites (LinkedIn, Facebook, Twitter, etc.)

- Maximum dissemination of your research work

Submit Your Paper Online: Click Here to Submit

Or Contact service@oalib.com 